\title{
Prevalence of Swine Gastrointestinal Parasites in Nyagatare District, Rwanda
}

\author{
M. Tumusiime $\mathbb{D},{ }^{1}$ P. Ntampaka $\mathbb{D}^{1},{ }^{1}$ F. Niragire $\mathbb{D}^{2},{ }^{2}$ T. Sindikubwabo $\mathbb{D},{ }^{1}$ and F. Habineza ${ }^{1}$ \\ ${ }^{1}$ Department of Veterinary Medicine, University of Rwanda, P. O. Box 57, Nyagatare, Rwanda \\ ${ }^{2}$ Department of Applied Statistics, University of Rwanda, P.O. Box 1514, Kigali, Rwanda
}

Correspondence should be addressed to P. Ntampaka; piusynt@gmail.com

Received 23 August 2020; Accepted 19 November 2020; Published 2 December 2020

Academic Editor: Eric Agola Lelo

Copyright ( 2020 M. Tumusiime et al. This is an open access article distributed under the Creative Commons Attribution License, which permits unrestricted use, distribution, and reproduction in any medium, provided the original work is properly cited.

\begin{abstract}
While pig farming has been growing rapidly in Rwanda, its potential contribution to the prevalence of zoonotic infections is not well known. Pig production is usually affected by gastrointestinal parasites, some of which are zoonotic and can threaten human health. The knowledge about the status of such infections is essential for policy decisions and interventions. We aimed to investigate the prevalence of swine gastrointestinal parasites in Nyagatare district, Rwanda. A cross-sectional study involved collecting 104 faecal samples from apparently healthy pigs. The floatation technique was used to identify the parasites and frequency distribution analysis, and Pearson chi-square tests of association were conducted for this study data. Overall, the prevalence of swine gastrointestinal parasites was $84.6 \%$, and the predominant species were Strongyle-type helminths representing 70.2\%, followed by coccidia (55.8\%), Strongyloides ransomi (39.4\%), and Ascaris suum (10.6\%). Of all parasitized pigs $(n=88), 84.1 \%$ developed coinfections involving 2, 3, or 4 different parasite species. The results showed a statistically significant correlation between the location of pigs and parasitic infections and that some prevalent parasites are zoonotic. Interventions among pig farmers in Nyagatare should aim to improve awareness and to provide information on the negative impacts of swine gastrointestinal parasites on pig production and human health.
\end{abstract}

\section{Introduction}

In 2018, pork production represented $21 \%$ of meat production in Rwanda and pig population was estimated to be $1,330,461$ [1]. Between 2013 and 2018, pig population in Rwanda increased by $76 \%$ [2]. The government of Rwanda expects to increase pork production from 19,945 to 67,676 metric tons of pork between 2017 and 2021 [3].

Among critical obstacles to such a country target are parasitic infections that can cause significant economic losses to pig production [4]. Swine parasites can live in different body parts of the hosts including the lungs (Metastrongylus spp.), kidney (Stephanurus dentatus), muscle (Cysticercus cellulosae, Toxoplasma gondii), and gastrointestinal tract $[5,6]$. The parasites of gastrointestinal tract include protozoa such as coccidia (Cystoisospora spp. and Eimeria spp.) and Entamoeba spp., as well as helminths. The latter include, among others, Strongyle-type helminths (Oesophagostomum spp., Hyostrongylus rubidus), Strongyloides spp., Ascaris spp., Trichuris spp., and Fasciolopsis spp. [7-9]. Pigs infected with gastrointestinal parasites grow slowly, can produce small litter size, and can die in case of heavy infection [10]. In addition, some parasites of pigs are responsible for zoonotic infections. These include among others Toxoplasma gondii, Trichinella spiralis, Taenia solium, Sarcocystis suihominis, Ascaris suum, Entamoeba pole$c k i$, and Fasciolopsis buski $[5,11-14]$. There is a wide range of transmission routes through which pigs can contract parasitic infections, among others, oral, colostral, and percutaneous. The oral transmission can occur through ingesting infective larva (Strongyle-type worms), embryonated eggs (Trichuris suis, Ascaris suum), items contaminated with metacercaria (Fasciolopsis spp.), cysts (Entamoeba spp.), or sporulated oocytes (coccidia) $[6,14,15]$. The transmission of Strongyloides ransomi involves the ingestion or suckling of items or colostrum contaminated with infective larvae as well as larval penetration of the host skin $[6,10]$.

During infection, gastrointestinal parasites can irritate intestinal mucosa and negatively affect the digestion and 


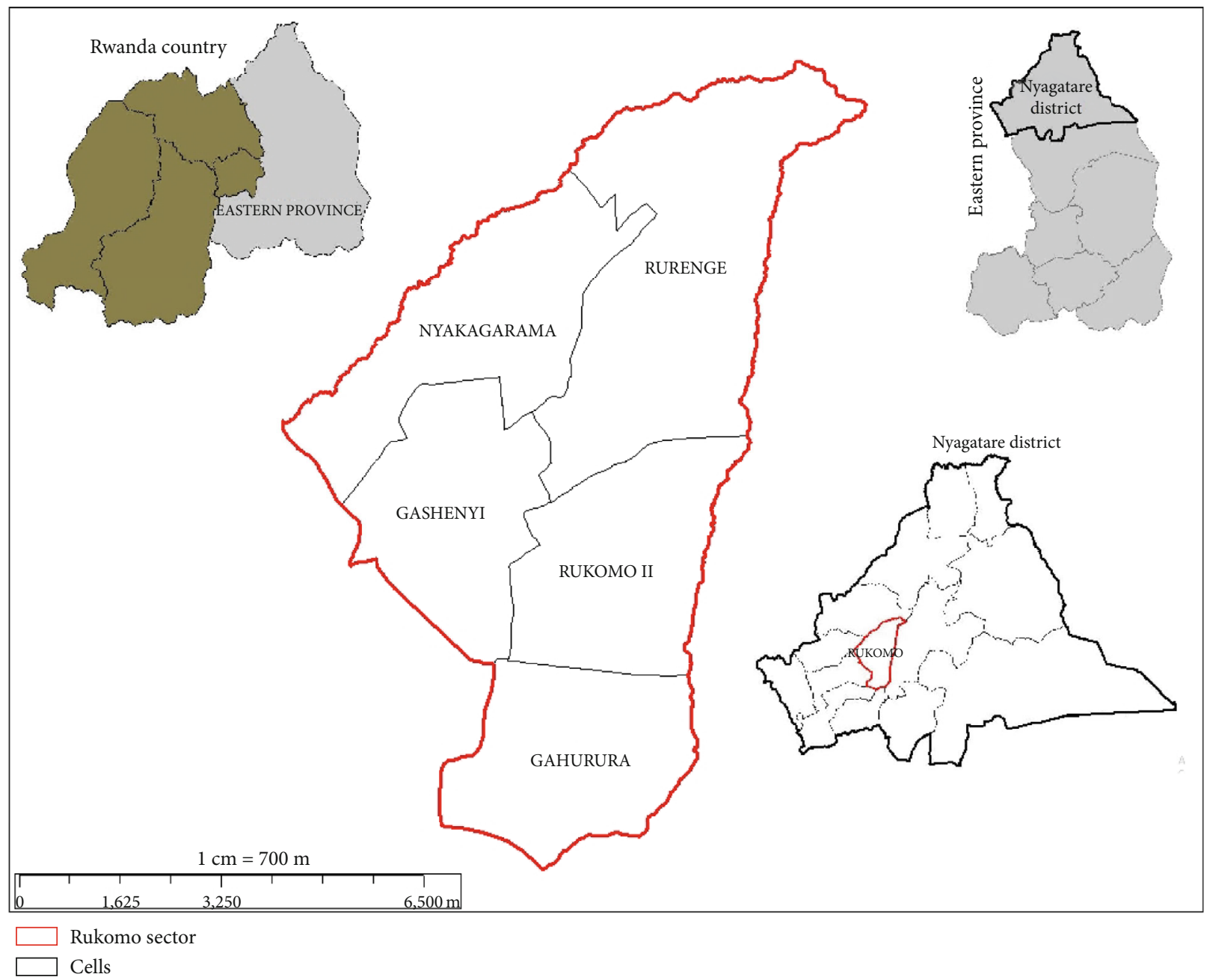

Figure 1: Map of Nyagatare district and the study area.

absorption of nutrients [8]. For instance, slight infection with Ascaris suum can decrease food intake and daily weight gain in infected animals $[9,16]$. Different factors can influence the prevalence of swine parasites including the system of management (intensive, semi-intensive, and extensive), on farm hygiene, geographical location, and antiparasitic prophylactic treatment such as deworming $[5,6,17,18]$. There are no published research works on gastrointestinal parasitoses of pigs in Rwanda and the information on such infections is scarce. In addition, studies carried out in other places reported the prevalence of gastrointestinal parasitoses in pigs that varies between $82 \%$ and $97 \%[19,20]$. This study determined the prevalence of swine gastrointestinal parasites in Nyagatare district, Rwanda. The study results are expected to provide valuable information about parasitic infections of pigs. The information can help in prioritising interventions to improve productivity of pig farming and to minimize the risk of transmitting zoonotic parasites to livestock and humans.

\section{Materials and Methods}

2.1. Study Area. The study was carried out in Nyagatare district, one of the 7 administrative districts of Eastern province,
TABLE 1: Overall prevalence of swine gastrointestinal parasites in Nyagatare district.

\begin{tabular}{lcc}
\hline Results & Number of pigs $(n=104)$ & Percent \\
\hline Negative & 16 & 15.4 \\
Positive & 88 & 84.6 \\
Total & 104 & 100.0 \\
\hline
\end{tabular}

Rwanda, between April and May 2019. Rwanda is in central East Africa, and it is administratively divided into 30 districts. Nyagatare district is divided into 14 sectors and 106 cells. It borders two districts, namely, Gatsibo (South) and Gicumbi (West), and two countries, namely, Uganda in the North and Tanzania in the East [21]. In 2012, the whole population of pigs in the Eastern province was estimated to be 104,000 and accounted for $10.5 \%$ of the pig population in Rwanda [1, 22].

In this study, Nyagatare district was purposively selected because it is an area dedicated to farming. It is a district with the highest cattle population in Rwanda and where pig production has been gaining attention. In addition, research in Nyagatare has mainly focused on cattle and small ruminants and has 
TABLe 2: Prevalence and test of association of gastrointestinal parasites with study locations $(n=104)$.

\begin{tabular}{|c|c|c|c|c|c|}
\hline \multirow{2}{*}{ Parasite } & \multicolumn{4}{|c|}{ Frequency } & \multirow{2}{*}{$\begin{array}{c}\text { Test of independence } \\
P \text { value }\end{array}$} \\
\hline & Site & Sample & Positive cases (\%) & Prevalence & \\
\hline \multirow{5}{*}{ Strongyle-type helminths } & Rukomo II & 20 & $17(23.3 \%)$ & $85 \%$ & \multirow{5}{*}{0.002} \\
\hline & Gashenyi & 39 & $27(37.0 \%)$ & $69.2 \%$ & \\
\hline & Nyakagarama & 31 & $25(34.2 \%)$ & $80.6 \%$ & \\
\hline & Rurenge & 14 & $4(5.5 \%)$ & $28.6 \%$ & \\
\hline & Total & 104 & $73(100 \%)$ & $70.2 \%$ & \\
\hline \multirow{5}{*}{ Entamoeba spp. } & Rukomo II & 20 & $1(50 \%)$ & $5 \%$ & \multirow{5}{*}{0.578} \\
\hline & Gashenyi & 39 & $1(50 \%)$ & $2.6 \%$ & \\
\hline & Nyakagarama & 31 & 0 & - & \\
\hline & Rurenge & 14 & 0 & - & \\
\hline & Total & 104 & $2(100 \%)$ & $1.9 \%$ & \\
\hline \multirow{5}{*}{ Coccidia } & Rukomo II & 20 & $13(22.4 \%)$ & $65.0 \%$ & \multirow{5}{*}{0.014} \\
\hline & Gashenyi & 39 & $20(34.5 \%)$ & $51.3 \%$ & \\
\hline & Nyakagarama & 31 & $22(37.9 \%)$ & $71.0 \%$ & \\
\hline & Rurenge & 14 & $3(5.2 \%)$ & $21.4 \%$ & \\
\hline & Total & 104 & $58(100 \%)$ & $55.8 \%$ & \\
\hline \multirow{5}{*}{ Strongyloides ransomi } & Rukomo II & 20 & $9(22.0 \%)$ & $45.0 \%$ & \multirow{5}{*}{0.237} \\
\hline & Gashenyi & 39 & $19(46.3 \%)$ & $48.7 \%$ & \\
\hline & Nyakagarama & 31 & $10(24.4 \%)$ & $32.3 \%$ & \\
\hline & Rurenge & 14 & $3(7.3 \%)$ & $21.4 \%$ & \\
\hline & Total & 104 & $41(100 \%)$ & $39.4 \%$ & \\
\hline \multirow{5}{*}{ Ascaris suum } & Rukomo II & 20 & $1(9 \%)$ & $5.0 \%$ & \multirow{5}{*}{0.778} \\
\hline & Gashenyi & 39 & $5(45.5 \%)$ & $12.8 \%$ & \\
\hline & Nyakagarama & 31 & $3(27.3 \%)$ & $9.7 \%$ & \\
\hline & Rurenge & 14 & $2(18.2 \%)$ & $14.3 \%$ & \\
\hline & Total & 104 & $11(100 \%)$ & $10.6 \%$ & \\
\hline \multirow{5}{*}{ Trichuris spp. } & Rukomo II & 20 & 0 & - & \multirow{5}{*}{0.074} \\
\hline & Gashenyi & 39 & $4(100 \%)$ & $10.3 \%$ & \\
\hline & Nyakagarama & 31 & 0 & - & \\
\hline & Rurenge & 14 & 0 & - & \\
\hline & Total & 104 & $4(100 \%)$ & $3.8 \%$ & \\
\hline \multirow{5}{*}{ Fasciolopsis spp. } & Rukomo II & 20 & 0 & - & \multirow{5}{*}{0.223} \\
\hline & Gashenyi & 39 & $1(25 \%)$ & $2.6 \%$ & \\
\hline & Nyakagarama & 31 & $3(75 \%)$ & $9.7 \%$ & \\
\hline & Rurenge & 14 & 0 & - & \\
\hline & Total & 4 & $4(100 \%)$ & $3.8 \%$ & \\
\hline
\end{tabular}

TABLe 3: Number of parasite categories detected per infected study pig according to sampling sites $(n=88)$.

\begin{tabular}{|c|c|c|c|c|c|c|}
\hline \multirow{2}{*}{ Sampling site } & \multicolumn{4}{|c|}{ Number of parasite categories } & \multirow{2}{*}{ Total } & \multirow{2}{*}{ Chi-square tests } \\
\hline & One & Two & Three & Four & & \\
\hline Rukomo II & 1 & 12 & 4 & 1 & 18 & \multirow{6}{*}{$X^{2}=9.546, P=0.388$} \\
\hline Gashenyi & 5 & 15 & 10 & 3 & 33 & \\
\hline Nyakagarama & 5 & 17 & 8 & 0 & 30 & \\
\hline Rurenge & 3 & 3 & 1 & 0 & 7 & \\
\hline Total & 14 & 47 & 23 & 4 & 88 & \\
\hline Percent & 15.9 & 53.4 & 26.1 & 4.5 & 100.0 & \\
\hline
\end{tabular}




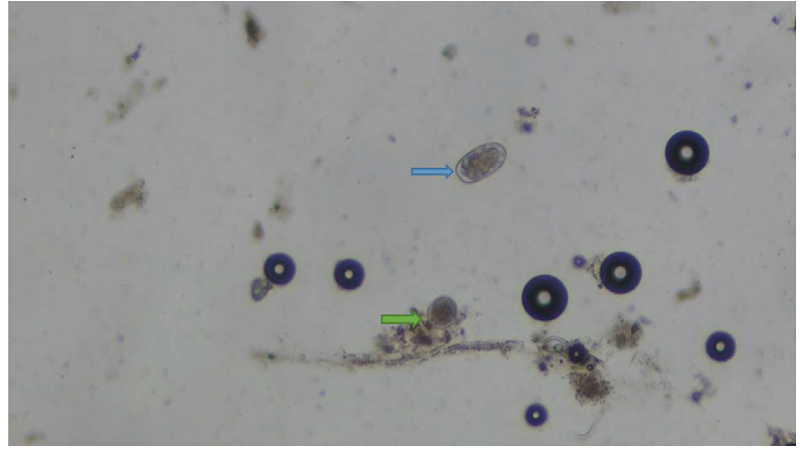

Figure 2: Strongyle-egg type (blue arrow) and Entameoba cyst (green arrow).

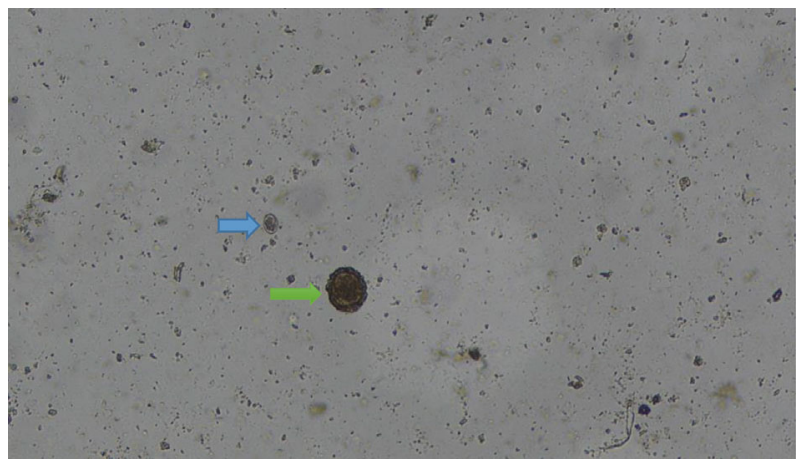

FIgure 3: Ascaris suum (green allow) and coccidian cyst (blue arrow).

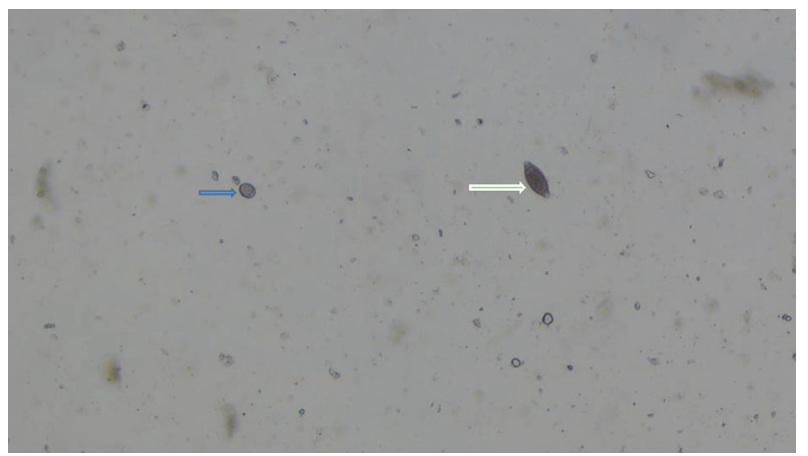

FIgURe 4: Coccidian cyst (blue arrow) and Trichuris suum (white arrow).

overlooked the importance of the fast-growing pig population in the district. Figure 1 shows the map of Nyagatare district and the study area. The figure shows Rukomo administrative sector (red limit) and four of its administrative cells (gray), namely, Rurenge, Nyakagarama, Gashenyi, and Rukomo II. These cells are the sampling sites in the present study.

2.2. Study Design and Sampling Procedure. The present crosssectional study involved collecting faecal samples from apparently healthy pigs younger than 1 year old and kept under semi-intensive system. In the first stage, cluster sampling was used to randomly select Rukomo administrative sector as a cluster in Nyagatare district. In the second stage, the study pigs were randomly selected across four adminis-

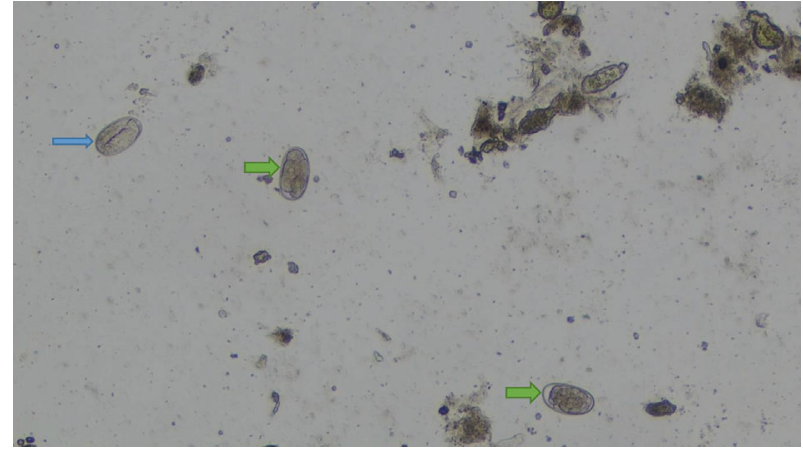

FIGURE 5: Strongyle-egg types (arrows green) and Strongyloides ransomi (blue arrow).

trative cells in Rukomo sector, namely, Gashenyi, Nyakagarama, Rukomo II, and Rurenge. Records showed that the pig population in the Rukomo sector was around 2500 in 2018. There were few pigs in Gahururu administrative cell, and thus, it was not considered in this study. For calculation of this study sample size, the prevalence of swine parasitoses in Rwanda was assumed to be $50 \%$ [23], as there was no prior knowledge about it.

With a level of precision of $10 \%$ and a $95 \%$ level of confidence, the minimum size $n$ of a representative sample was computed using Cochran's sample size formula for proportions, given as Equation (1) [23].

$$
n=\frac{\left(Z^{2} \cdot p(1-p)\right) / e^{2}}{1+\left(\left(Z^{2} \cdot p(1-p)\right) / e^{2} N\right)}=96
$$

where $N$ is the pig population size.

The population of Rwanda is usually responsive to health research studies, but they are not familiar with studies on domestic animals; thus, we increased the computed sample size by $10 \%$ to compensate for possible nonresponse [24]. Therefore, this study targeted a total sample size of 106 pigs of whom 104 were successfully sampled.

2.3. Collection of Samples. Prior to collecting the samples, pig farmers were briefed about the purpose of the study. Faecal samples were collected from pigs owned by the farmers who authorised sampling of their animals.

The samples were collected from rectum using gloved fingers, put in a stool container, and transported in a cool box. In the laboratory, the samples were kept refrigerated and analysed the following day. The analysis was performed at the laboratory of the School of Veterinary Medicine of the University of Rwanda. The samples were processed by floatation method for nematode eggs and protozoal ova and cysts while sedimentation technique was used for trematode eggs. The preparation of floatation fluid involved dissolving $400 \mathrm{~g}$ of sodium chloride in a litre of tap water, that is, the fluid had a specific gravity of 1.200 . The samples were prepared by mixing $3 \mathrm{~g}$ of faeces in $50 \mathrm{ml}$ of floatation fluid [25]. The suspension was filtered through a tea strainer into a beaker and then transferred to a test tube until a positive meniscus was reached. Then, a cover slip was put on top of 

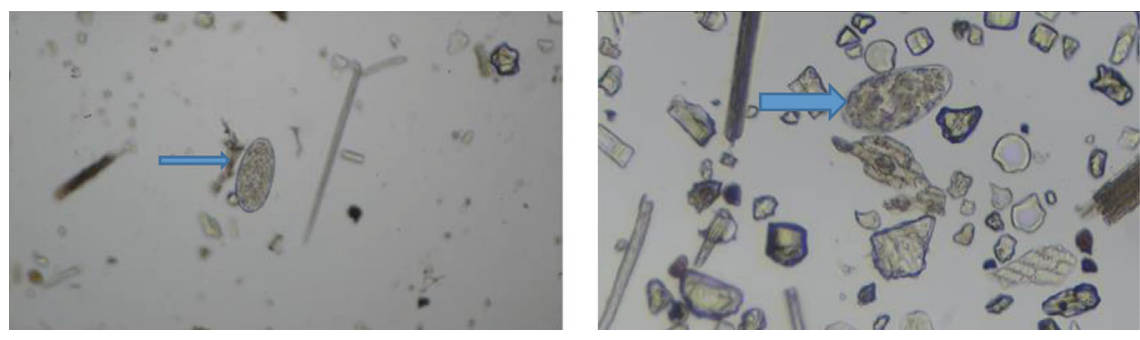

FIGURE 6: Fasciolopsis spp. (blue arrows).

the test tube for 10 minutes after which it was removed and mounted on a microscope slide. To perform the sedimentation, $3 \mathrm{~g}$ of faeces was dissolved into $100 \mathrm{ml}$ of water in a beaker, and then, the suspension was filtered using a tea strainer into another beaker and left to sediment for 10 minutes. After 10 minutes, the supernatant was removed carefully leaving the sediment, and then, $100 \mathrm{ml}$ of water was added to the sediment, and the same process was repeated three times. At the end of the third time, the sediment was put on a microscopic slide and examined under a microscope. Based on their size and shape, the eggs or cysts of gastrointestinal parasites were identified under microscope at 10x magnification [26].

2.4. Data Analysis. The sample test results together with respective information on the location (cell) of the sampled pigs were entered into IBM Statistical Package for Social Sciences (SPSS) version 23. Frequency distribution analysis was performed, and the overall prevalence was calculated. To compute the prevalence, the number of pigs infected with gastrointestinal parasites was divided by the total number of sampled pigs multiplied by hundred.

Any association between the prevalence of gastrointestinal parasites and sampling sites was assessed using Pearson chi-square test of independence [27]. The results were considered significant at $5 \%$ level of significance.

\section{Results}

The data were successfully collected from 104 pigs younger than 1 year old and kept under semi-intensive system. Overall estimate of the prevalence of gastrointestinal parasites in study pigs is presented in Table 1 .

The results in Table 1 show that the overall prevalence of swine gastrointestinal parasites was $84.6 \%$. Administrative cell-level-specific prevalence of different gastrointestinal parasites and tests of association with sampling sites are shown (Table 2).

The results in Table 2 indicate that there is a statistically significant association between the prevalence of Strongyletype worms and coccidia with the location of the pigs (sampling sites).

The relationship between sampling sites and the number of parasite species detected per study pig is indicated in Table 3.

Of all infected pigs, $84.1 \%$ developed coinfection, and majority $(53.4 \%)$ were infected with two types of parasites. The results in Table 3 show that the number of parasite categories is not significantly influenced by the geographical location of the pigs across the sampling sites. Figures 2-6 illustrate eggs and cysts of the parasites.

\section{Discussion}

This study aimed at investigating gastrointestinal parasites in pigs in Nyagatare district, and the findings can help in prioritising interventions for improving productivity of pig farming and minimizing the risk of transmitting zoonotic parasites to livestock and humans. The overall prevalence of gastrointestinal parasites was $84.6 \%$, and three of the identified types of parasites are zoonotic, including Ascaris suum, Fasciolopsis spp., and Entamoeba spp. Our findings also show that the prevalence of Strongyle-type helminths and coccidia in pigs in Nyagatare was significantly associated with the geographical location of the pigs.

The prevalence rates for some parasites were very high, while they were relatively lower for others compared to previous studies conducted in different countries. For instance, the study overall prevalence of gastrointestinal parasites reported in this study was lower than 91\%, 93\%, and $97 \%$ reported in studies conducted in Ghana, Burkina Faso, and China, respectively $[20,28,29]$. However, it was higher than $82 \%$ reported by Nsoso et al. in Botswana [19]. The prevalence of $70.2 \%$ recorded for Strongyle-type helminths in the present study was higher than $52 \%$ reported by Boes et al. in China [20].

This study prevalence of coccidia (55.8\%) was lower than $47.2 \%$ and $40.7 \%$ reported by Weng et al. in China and Roesel et al. in Uganda, respectively [30, 31]. However, it was higher than that conducted by Karamon et al. in Poland [32] which found that $27.8 \%$ of investigated piglets had Isopsora (Cystoisospora) suis while $2.6 \%$ had Eimeria spp. This study prevalence of $39.4 \%$ for Strongyloides ransomi was higher than $4.2 \%$ reported in Uganda by Roesel et al. [31]. One of the important factors that can explain the difference in prevalence is thought to be the production system. All the pigs investigated in this study were reared under semi-intensive system while pigs investigated by Roesel et al. in Uganda [31] were reared under different production systems including intensive, semi-intensive, and extensive.

Compared to the studies conducted in Uganda and Tanzania [10,31], the prevalence of Ascaris suum was lower in Uganda and higher in Tanzania than in Nyagatare, Rwanda. Apart from Ascaris suum, two other types of potential zoonotic parasites, namely, Fasciolopsis spp. and Entamoeba spp., were also identified. 
Fasciolopsis buski is a zoonotic parasite, and it is prevalent in pigs in different Asian countries and has been reported in Africa, for instance, in Nigeria [33, 34]. There are no published studies on fasciolopsis in Rwanda, but it is a food-borne infection, and humans develop it after they eat raw aquatic vegetation or food plants contaminated with metacercariae [33]. Pigs can develop amoebiasis due to Entamoeba suis and E. polecki, and the latter one is a zoonotic species [13].

Other common zoonotic parasites include Taenia solium, Trichinella spiralis, Toxoplasma gondii, and Sarcocystis suihominis [11, 17]. A study conducted in southern part of Rwanda found that larvae of Taenia solium (Cysticercus cellulosae) caused $23.3 \%$ of epileptic cases in people [35]. There is no information about the prevalence of trichinellosis in humans and pigs in the study area and in Rwanda at large.

Although there are no published studies on toxoplasmosis in animals in Rwanda, a study carried out in pregnant women in Kigali found that $12.2 \%$ were positive for Toxoplasma gondii and that the occurrence was associated with drinking unclean water and eating undercooked meat [36].

Similar to reports by Nansen and Roepstorff [37] and by Roesel et al. [31], the present study showed that the geographical location of the pigs was significantly associated with the prevalence of Strongyle-type helminths and coccidia in pigs in Nyagatare. We found that the rate of mixed infections in pigs suffering from parasitoses represented $84.1 \%$, and it was higher than 7\% reported by Atawalna et al. in Ghana [4]. It is more likely that coinfections found in this study would considerably contribute to the reduction of the production and performance of the pigs [10]. Although pig farmers may not be aware due to subclinical infections, economic losses caused by endoparasites are important [17].

\section{Conclusions}

The prevalence of swine gastrointestinal parasites was as high as $84.6 \%$, and the predominant species were strongyle-type helminths, followed by coccidia. The prevalence of gastrointestinal parasites is high and varies according to the location of the pig in Nyagatare, Rwanda. In addition, some detected parasites including Ascaris suum, Fasciolopsis spp, and Entameoba spp. are zoonotic. The intervention is needed to raise awareness among pig farmers about negative impacts on pig farming productivity and on other livestock as well as on human health.

\section{Data Availability}

All relevant data collected and analysed during this study are within the manuscript.

\section{Conflicts of Interest}

The authors declare that there is no conflict of interest regarding this paper.

\section{Acknowledgments}

We would like to thank the pig farmers for allowing faecal sampling of pigs. We are also thankful to the University of Rwanda for allowing analysis of faecal samples at their laboratory.

\section{References}

[1] Ministry of Agriculture and Animal Resources (MINAGRI), Annual report 2018-2019, MINAGRI, Republic of Rwanda, 2019.

[2] The New Times. High income, appetite for pork, drive up pig industry, 2018, May 2020, http://www.newtimes.co.rw/news/ high-income-appetite-pork-drive-pig-industry.

[3] B. I. Shapiro, G. Gebru, S. Desta, and K. Nigussie, Rwanda livestock master plan, International Livestock Research Institute, Nairobi, Kenya, 2017, https://cgspace.cgiar.org/handle/10568/ 104049.

[4] J. Atawalna, R. D. Folitse, and C. Amenakpor, "Prevalence of gastrointestinal parasites among pigs in the Ejisu Municipality of Ghana," Scholars Journal of Agriculture and Veterinary Sciences, vol. 3, pp. 33-36, 2016.

[5] H. R. Gamble, "Parasites associated with pork and pork products," Revue Scientifique et Technique-Office International des Epizooties, vol. 16, no. 2, pp. 496-506, 1997.

[6] A. Roepstorff and P. Nansen, Epidemiology, diagnosis, and control of helminth parasites of swine, FAO, Rome, 1998.

[7] M. F. Mendoza-Gómez, A. Pulido-Villamarín, A. BarbosaBuitrago, and M. Aranda-Silva, "Presence of gastrointestinal parasites in swine and human of four swine production farms in Cundinamarca-Colombia," Revista MVZ Cordoba, vol. 20, pp. 5014-5027, 2015.

[8] M. A. Geresu, Z. Hailemariam, G. Mamo, M. Tafa, and M. Megersa, "Prevalence and associated risk factors of major gastrointestinal parasites of pig slaughtered at Addis Ababa Abattoirs Enterprise, Ethiopia," Journal of Veterinary Science \& Technology, vol. 6, no. 4, 2015.

[9] C. M. Krishna Murthy, K. J. Ananda, J. Adeppa, and M. G. Satheesha, "Studies on gastrointestinal parasites of pigs in Shimoga region of Karnataka," Journal of Parasitic Diseases, vol. 40, no. 3, pp. 885-889, 2016.

[10] H. E. Nonga and N. Paulo, "Prevalence and intensity of gastrointestinal parasites in slaughter pigs at Sanawari slaughter slab in Arusha, Tanzania," Livestock Research for Rural Development, vol. 27, 2015.

[11] O. Djurković-Djaković, B. Bobić, A. Nikolić, I. Klun, and J. Dupouy-Camet, "Pork as a source of human parasitic infection," Clinical Microbiology and Infection, vol. 19, no. 7, pp. 586-594, 2013.

[12] M. Dutto and N. Petrosillo, "Hybrid ascaris suum/lumbricoides (ascarididae) infestation in a pig farmer: a rare case of zoonotic ascariasis," Central European journal of public health, vol. 21, no. 4, pp. 224-226, 2013.

[13] T. Ji, H.-X. Cao, R. Wu et al., "Prevalence and genetic identification of ThreeEntamoebaSpecies in pigs in Southeastern China," BioMed Research International, vol. 2019, 8 pages, 2019.

[14] J. Ma, M.-M. Sun, J.-J. He et al., "Fasciolopsis buski (Digenea: Fasciolidae) from China and India may represent distinct taxa 
based on mitochondrial and nuclear ribosomal DNA sequences," Parasites \& vectors, vol. 10, no. 1, p. 101, 2017.

[15] G. D. Schmidt, L. S. Roberts, and J. Janovy, Foundations of parasitology, McGraw-Hill, Saint Louis: Mosby, 8th edition, 2009.

[16] S. K. Tidi, F. A. Ella, and A. B. Ella, "Prevalence of gastrointestinal parasites of pigs in Jos, Plateau State, Nigeria," Nigerian Journal of Parasitology, vol. 32, pp. 37-40, 2011.

[17] K. K. Agustina, I. B. N. Swacita, I. B. M. Oka et al., "Reducing zoonotic and internal parasite burdens in pigs using a pig confinement system," Veterinary World, vol. 10, no. 11, pp. 13471352, 2017.

[18] B. Mushonga, G. Habarugira, A. Birori, E. Kandiwa, A. Samkange, and E. Bhebhe, "An epidemiological survey of the magnitude and local perceptions of porcine cysticercosis by two methods in Nyaruguru district, Rwanda," Veterinary Parasitology: Regional Studies and Reports, vol. 14, pp. 18-24, 2018.

[19] S. J. Nsoso, K. P. Mosala, R. T. Ndebele, and S. S. Ramabu, "The prevalence of internal and external parasites in pigs of different ages and sexes in Southeast District, Botswana," Onderstepoort Journal of Veterinary Research, vol. 67, no. 3, pp. 217-220, 2000.

[20] J. Boes, A. L. Willingham, S. Fuhui et al., "Prevalence and distribution of pig helminths in the Dongting Lake Region (Hunan Province) of the People's Republic of China," Journal of Helminthology, vol. 74, no. 1, pp. 45-52, 2000.

[21] Nyagatare district, District potentialities assessment for the integrated and self-centered local economic development, Republic of Rwanda, 2013.

[22] National Institute of Statistics of Rwanda, "Ministry of finance and economic planning," in Rwanda Fourth Population and Housing Census, 2012, National Institute of Statistics of Rwanda and the Ministry of Finance and Economic Planning, Republic of Rwanda, 2014.

[23] W. G. Cochran, Sampling Techniques, John Wiley \& Sons, New York, 3rd edition, 1977.

[24] L. Naing, T. Winn, and B. N. Rusli, "Practical issues in calculating the sample size for prevalence studies," Archives of orofacial Sciences, vol. 1, pp. 9-14, 2006.

[25] J. Hansen and B. Perry, The Epidemiology, Diagnosis, and Control of Helminth Parasites of Ruminants, International laboratory for Reseach on Animal Health, Nairobi, Second edition, 1994.

[26] M. A. Taylor, R. L. Coop, and R. L. Wall, Veterinary Parasitology, blackwell Publishing Ltd, UK, Third edition, 2007.

[27] M. L. McHugh, "The chi-square test of independence," Biochemia medica, vol. 23, no. 2, pp. 143-149, 2013.

[28] A. Permin, L. Yelifari, P. Bloch, N. Steenhard, N. P. Hansen, and P. Nansen, "Parasites in cross-bred pigs in the Upper East Region of Ghana," Veterinary Parasitology, vol. 87, no. 1, pp. 63-71, 1999.

[29] H. H. Tamboura, H. Banga-Mboko, D. Maes et al., "Prevalence of common gastrointestinal nematode parasites in scavenging pigs of different ages and sexes in eastern centre province, Burkina Faso," Onderstepoort Journal of Veterinary Research, vol. 73, no. 1, pp. 53-60, 2006.

[30] Y. B. Weng, Y. J. Hu, Y. Li et al., "Survey of intestinal parasites in pigs from intensive farms in Guangdong Province, People's Republic of China," Veterinary Parasitology, vol. 127, no. 3-4, pp. 333-336, 2005.
[31] K. Roesel, I. Dohoo, M. Baumann, M. Dione, D. Grace, and P. H. Clausen, "Prevalence and risk factors for gastrointestinal parasites in small-scale pig enterprises in central and eastern Uganda," Parasitology Research, vol. 116, no. 1, pp. 335-345, 2017.

[32] J. Karamon, I. Ziomko, and T. Cencek, "Prevalence of Isospora suis and Eimeria spp. in suckling piglets and sows in Poland," Veterinary parasitology, vol. 147, no. 1-2, pp. 171-175, 2007.

[33] P. K. Prasad, L. Mohan Goswami, V. Tandon, and A. Chatterjee, "PCR-based molecular characterization and insilico analysis of food-borne trematode parasites Paragonimus westermani, Fasciolopsis buski and Fasciola gigantica from Northeast India using ITS2 rDNA," Bioinformation, vol. 6, no. 2, pp. 64-68, 2011.

[34] I. O. Igbokwe and C. V. Maduka, "Maladies affectant la production porcine au Nigeria : synthèse des questions et des défis actuels," Revue d'élevage et de médecine vétérinaire des pays tropicaux, vol. 71, pp. 87-95, 2018.

[35] R. Rottbeck, J. F. Nshimiyimana, P. Tugirimana et al., "High prevalence of cysticercosis in people with epilepsy in southern Rwanda," PLoS Neglected Tropical Diseases, vol. 7, no. 11, article e2558, 2013.

[36] E. Murebwayire, K. Njanaake, J. C. S. Ngabonziza, W. Jaoko, and K. J. Njunwa, "Seroprevalence and risk factors of Toxoplasma gondii infection among pregnant women attending antenatal care in Kigali, Rwanda," Tanzania Journal of Health Research, vol. 19, no. 1, 2017.

[37] P. Nansen and A. Roepstorff, "Parasitic helminths of the pig: factors influencing transmission and infection levels," International Journal for Parasitology, vol. 29, no. 6, pp. 877-891, 1999. 